\title{
Effect of chest physiotherapy on blood gases of neonates treated by intermittent positive pressure respiration
}

\author{
R. HOLLOWAY, E. B. A DAMS,S. D. DESAI, AND \\ A. K. TH A M B I R A N \\ From the Respiratory Unit, University of Natal and King Edward VIII Hospital, Durban, South Africa
}

\begin{abstract}
The effect of standardized chest physiotherapy and hyperinflation on the blood gases of neonates being treated for tetanus by intermittent positive pressure respiration was investigated. It was found that physiotherapy and suction to remove secretions did not improve oxygen pressures but produced a small drop in both $\mathrm{PaCO}_{2}$ and $\mathrm{PaO}_{2}$. This was associated with a widening of the alveolar to arterial gradient for oxygen. During the hour that followed, blood oxygen pressure slowly returned to pre-physiotherapy levels. This could be hastened by hyperinflation (increasing the pressure delivered to the baby) after physiotherapy. Although hyperinflation restored blood oxygen pressures, it did so by a mechanism which left alveolar to arterial oxygen gradients unchanged. Moderate hyperinflation without physiotherapy produced small increases in blood oxygen tension, but also failed to restore completely arterial oxygen pressures of neonates on I.P.P.R. The results are discussed.
\end{abstract}

In common with others (Nealon, Prorok, Gosin, Fraimow, 1966 ; Gold and Helrich, 1967 ; Bendixen, Hedley-Whyte, and Laver, 1963), we have found a wide alveolar to arterial oxygen pressure gradient $\left(\mathrm{PAaO}_{2}\right)$ and failure to maintain normal arterial oxygenation among patients being ventilated on air by intermittent positive pressure respiration (I.P.P.R.) (Holloway, Desai, Kelly, Thambiran, Strydom, and Adams, 1966).

This is not an insurmountable difficulty since oxygen enrichment of inspired air can elevate oxygen tension and prevent hypoxaemia, but it is preferable to find the cause for low arterial oxygen and to remove it. This turns out to be a formidable task, since I.P.P.R. and the complications which attend it (such as infection) disturb practically every aspect of lung function. It could be said that whether the patient can oxygenate his blood or not resolves itself into a matter of how efficient he is at adapting to the many disturbances.

Even though this is true and it is likely that not one but many causes exist, it should be possible to tackle the problem piecemeal. For example, reversing atelectasis would eliminate one cause for hypoxaemia. Blood entering areas of lung not being ventilated constitutes a shunt across the lung

Requests for reprints to be addressed to R. Holloway and contributes to the increased $\mathrm{PAaO}_{2}$. The same would apply to areas of lung receiving gas but not enough for the blood flow. It might be possible to improve oxygenation by opening up areas of atelectasis or removing secretions which block bronchi.

One method of doing this is by means of chest physiotherapy. But while this is advocated for the removal of secretions, we could find no evidence that it improves oxygenation, and so we became interested in the effects of standardized chest physiotherapy on the arterial oxygen pressures of neonates being treated for tetanus by I.P.P.R.

The results of a preliminary investigation (Holloway et al., 1966) showed that instead of a rise in pressure there was actually a fall, though in the hour that followed this slowly corrected itself until the $\mathrm{PaO}_{2}$ had returned to its control value.

Since then we have repeated the work and also investigated the effect of hyperventilation combined with physiotherapy on the abnormally low $\mathrm{PaO}_{2}$. Hyperinflation has taken our interest since devices are available which automatically hyperinflate the lungs of patients on I.P.P.R. (Feychting and Settergren, 1966 ; Korkeila, 1968). These have arisen following observations that high inflation 
pressures reverse short-standing hypoxia in patients on I.P.P.R. (Bendixen, Bullwinkel, HedleyWhyte, and Laver, 1964). It is thought that I.P.P.R. might cause hypoxaemia by preventing the occasional sigh.

\section{MATERIAL}

Fifty-one neonates in the first 20 days of life were studied. They were divided into three groups.

A group of 14 spontaneously breathing babies from the hospital obstetric unit who had no known abnormality (group A) were selected to match the patients with respect to age. Using the same technique as for the patients, their resting $\mathrm{PaO}_{2}$ and $\mathrm{PaCO}_{2}$ were measured. These levels served as normal standards.

Out of a second group of 22 patients (group B) being treated for tetanus neonatorum by I.P.P.R. 10 received physiotherapy followed by an increase in inflation pressure of $10 \mathrm{~cm} . \mathrm{H}_{2} \mathrm{O}$ for 10 minutes. The other 12 received physiotherapy but no increase in inflation pressure. The decision whether or not to hyperinflate was randomized, and the technologist analysing for blood gases did not know whether an increase in pressure had been brought about.

A third group of 15 neonates on I.P.P.R. (group C) were randomly allocated to two groups. Eight received increase in pressure, while the remainder received no increase. The same double blind procedure was used, but in this case none of the babies received physiotherapy and hyperinflation was continued for 30 minutes.

\section{METHODS}

The patients were all curarized and given I.P.P.R. via a cuffed tracheostomy tube which inflated only during the positive phase of the respirator (Holloway and Thambiran, 1967). They were ventilated by means of either Radcliffe or Bennett respirators. When Bennett machines were used, the pressure wave was made to approximate that of the Radcliffe, which generates a sudden rise in pressure followed by a period when the pressure is held constant and finally falls suddenly (square wave). Pressure increases in those patients who were hyperinflated were brought about by suitable adjustments of the machines. Rate and all other respirator variables were held constant.

Arterialized blood was obtained from the scalp of the babies using the method of arterialization described by Saling (1964). In our hands this gives acceptable correlation between arterial and arterialized blood (Desai, Holloway, Thambiran, and Wesley, 1967). Duplicate samples were obtained from all subjects. The $p \mathrm{H}$ and $\mathrm{PcO}_{2}$ were measured using a micro-technique (Siggaard Andersen, Engel, J $\varnothing$ rgensen, and Astrup, 1960). $\mathrm{PaO}_{2}$ was measured with a modification of the Clarke electrode which allowses the measurement of microsamples (Desai, Hollowayo and Thambiran, 1968).

The $p \mathrm{H}$ electrode was calibrated using precisisn buffers $(p \mathrm{H} 7.381$ and 6.840$)$ at $38^{\circ} \mathrm{C}$. The $\mathrm{Po}_{2}$ elec- $\mathrm{D}$ trode was calibrated using warm $\left(38^{\circ} \mathrm{C} . \pm 0 \cdot 1^{\circ} \mathrm{C} \text {. }\right)^{\circ}$ water in equilibrium with air $\left(\mathrm{Po}_{2}=20.9 \times \mathrm{PB}-47^{\infty}\right.$ $\mathrm{mm} . \mathrm{Hg}$ ) and a solution whose $\mathrm{PO}_{2}$ was taken to be: $\overrightarrow{\mathrm{O}}$ zero (sodium sulphite in $0.04 \%$ Borax). Calibrations were made at frequent intervals during $\vec{\omega}$ the measurement of $\mathrm{PO}_{2}$ and $p \mathrm{H}$. At less frequent intervals the $\mathrm{Po}_{2}$ electrode was standardized with $\times$ blood brought into equilibrium with gases of knowni composition. Used in this way, the electrode error was found to be $4 \mathrm{~mm}$. $\mathrm{Hg}$ (S.E. $1.9 \mathrm{~mm}$. Hg). The gas mixtures used for calibration were prepared in ${ }_{-}$ this unit (Brachi, Christopher, Mack, and Holloway,o 1967) and analysed by means of a Lloyd Haldane apparatus which in our hands gives the total analys- $\vec{c}$ able gas of room air as $20 \cdot 93$, S.D. $0 \cdot 05$.

\section{PROCEDURE}

Group B A control sample was obtained and, while this was being analysed, a physiotherapist performed

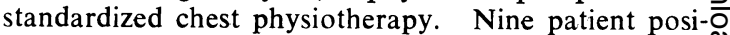
tions were used-supine. left side lying, and rightô side lying ; in each, the cot was flat for the first part, $\mathbb{Q}$ head elevated for the second part, and feet elevated $\overrightarrow{\vec{B}}$ for the last.

Physiotherapy took the form of clapping, com-? pression vibration, and the removal of secretions by suction until the lung underlying the operator's hand was considered to be clear. The criteria upon which the clearness or otherwise of the lung were based were the absence of rhonchi to both auscultation and $\frac{\times}{\sigma}$ palpation, adequacy of chest movement, and the 3 sounds of air entry. For suction No. 3 French gauge catheters with side openings were used. They윽 were introduced $7-8 \mathrm{~cm}$. into the tracheostomy tube and, used in this way, they never entered a bronchus 음 whose diameter was less than twice their own. This $D$ was considered necessary as a precaution against col-으․ lapse of lung (Rosen and Hillard, 1962).

Immediately after physiotherapy, a second sample or of blood was taken. In patients in group B who $\mathrm{O}$ received hyperinflation, this was followed by a third N sample at the end of 10 minutes' hyperinflation. The $\sigma$ controls observed for the behaviour of the blood gases after physiotherapy were left undisturbed be- $\stackrel{0}{-}$ tween the second and third samples. A fourth sample $\mathbb{D}$ was taken from all patients of group B after a final ${ }^{+}$ period of one hour during which the respirators were $\frac{T}{0}$ reset to control values.

Group C A control sample was taken and, follow-ฉ̊ ing this, some received hyperinflation while others were left undisturbed. At the end of 30 minutes blood $?$ was taken from both groups. 


\section{RESULTS}

GROUPS A AND B

Arterial oxygen pressure The mean $\mathrm{PaO}_{2}$ of the neonates ventilated on air for 10 minutes prior to the investigation was found to be $50.6 \mathrm{~mm}$. $\mathrm{Hg}$, S.D. $6.4 \mathrm{~mm}$. $\mathrm{Hg}(\mathrm{N}=34)$, compared to $76.0 \mathrm{~mm}$. $\mathrm{Hg}$, S.D. $5.0 \mathrm{~mm}$. $\mathrm{Hg}(\mathrm{N}=14)$ in a group of normal babies (Figure).
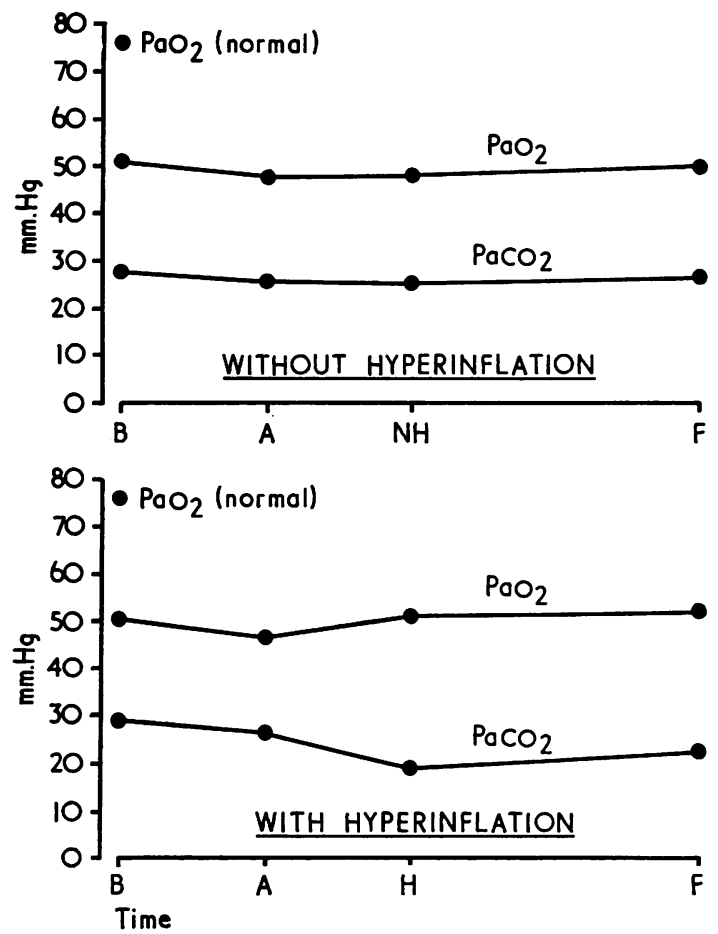

FIGURE. Effect on arterial gas pressure (ordinate) of standardized chest physiotherapy and hyperinflation. Upper graph shows what happened during physiotherapy without hyperinflation, while lower shows effect of hyperinflation following physiotherapy.

$\mathrm{PaO}_{2}=$ partial pressure of oxygen in arterial blood; $\mathrm{PaCO}_{2}$ = partial pressure of carbon dioxide in arterial blood; $\mathrm{PaO}_{2}$ (normal) $=$ the arterial pressure found among a group of controls matched for age; $B=$ before physiotherapy; $A=$ after physiotherapy; $\mathrm{NH}=$ no hyperinflation; $\mathrm{H}=$ hyperinflation; $F=$ final.

The $\mathrm{PaO}_{2}$ of the respirator babies, which was already significantly lower than those of the normal children $(P<0.001)$ dropped even lower to 47 $\mathrm{mm}$. Hg, S.D. $6.4 \mathrm{~mm}$. $\mathrm{Hg}(\mathrm{N}=34)$ (Figure) after chest physiatherapy. This small drop was significant $(\mathrm{P}<0.05)$.
In the first 10 minutes following physiotherapy there was a slow increase in mean $\mathrm{PaO}_{2}$ of 1.7 $\mathrm{mm}$. $\mathrm{Hg}$, S.D. $1.25 \mathrm{~mm}$. $\mathrm{Hg}$, which continued so that by the end of an hour the deficit had been made up and there was no significant difference between the control levels and the final level.

This return to resting value could be accelerated by increasing inflation pressures by $10 \mathrm{~cm} . \mathrm{H}_{2} \mathrm{O}$ in the 10-minute period immediately following physiotherapy. Hyperinflation produced an increase in mean $\mathrm{PaO}_{2}$ of $6.4 \mathrm{~mm}$. $\mathrm{Hg}$, S.D. $3 \cdot 1$ $(\mathrm{N}=14)$, over the 10 -minute period, which is significantly greater than the spontaneously occurring increase $(P<0.001)$ over the same period.

Even though the mean rise due to hyperinflation was greater than the mean fall due to physiotherapy, the difference was very small and the $\mathrm{PaO}_{2}$ of the hyperinflated babies did not differ significantly from control.

Hyperinflation also produced a fall in mean $\mathrm{PaCO}_{2}$ from $26.6 \mathrm{~mm}$. $\mathrm{Hg}$, S.D. $5.6 \mathrm{~mm}$. $\mathrm{Hg}$ $(\mathrm{N}=14)$ to $19.2 \mathrm{~mm}$. $\mathrm{Hg}$, S.D. $8.6 \mathrm{~mm}$. $\mathrm{Hg}$ $(\mathrm{N}=14)$. This significant $(\mathbf{P}<0.02)$ fall in $\mathrm{PaCO}_{2}$ indicates that alveolar ventilation was increased as a result of increasing inflation pressure.

Alveolar to arterial oxygen gradient By means of a rearrangement of the ideal alveolar gas equation (Rahn and Fenn, 1955), and substituting $k$ for $\frac{R}{\left(1-\mathrm{FIO}_{2}+\mathrm{FIO}_{2} \mathrm{R}\right)}$ the following equation is arrived at: where

$$
\mathrm{PaO}_{2}=\mathrm{PIO}_{2}-\mathrm{PaCO}_{2} / \mathrm{k}-\mathrm{PAaO}_{2}
$$

$\mathrm{PaO}_{2}=$ arterial oxygen tension $(\mathrm{mm} . \mathrm{Hg}$ )

$\mathrm{PIO}_{2}=$ inspired oxygen tension $(\mathrm{mm} . \mathrm{Hg})$

$\mathrm{PaCO}_{2}=$ arterial carbon dioxide $(\mathrm{mm} . \mathrm{Hg}$ )

It is assumed that this is equal to alveolar $\mathrm{PCO}_{2}$.

$\mathrm{PAaO}_{2}=$ alveolar to arterial gradient for oxygen $(\mathrm{mm}$. $\mathrm{Hg}$ )

$$
\mathrm{k}=\frac{\mathrm{R}}{1-\mathrm{FIO}_{2}+\mathrm{FIO}_{2} \mathrm{R}}
$$

If the inspired oxygen tension is kept constant, as was the case during the present investigation, the difference in $\mathrm{PaO}_{2}$ between one set of figures and another on the same baby can be found and is given by the equation:

$$
\Delta \mathrm{PaO}_{2}=-\Delta \mathrm{PaCO}_{2} / \mathrm{k}-\Delta \mathrm{PAaO}_{2}
$$

which can be rearranged to give:

$$
\Delta \mathbf{P A a O}_{2}=-\Delta \mathbf{P a C O}_{2} / \mathbf{k}-\Delta \mathbf{P a O}_{2}
$$

where the value of $k$ varies from $1 \cdot 15(R=1 \cdot 2)$ to 0.91 . $(R=0.8)$.

This final equation can be used to estimate the alterations in alveolar to arterial oxygen gradient 
which occurred during physiotherapy. Since we were concerned mainly with the direction of changes rather than their magnitude, and since there is no way of knowing what the $R$ value of each patient was, we have chosen to use $R=1$ for calculations of $\Delta \mathrm{PAaO}_{2}$, and the figures given below are based upon this value. The magnitude of the changes which actually occurred would have been either slightly larger or smaller, depending upon which value of $R$ actually held during the measurements.

Under these conditions, the mean change in $\mathrm{PAaO}_{2}$ was an increase of $6.2 \mathrm{~mm}$. Hg, S.D. 3.96 $\mathrm{mm}$. $\mathrm{Hg} \quad(\mathbf{N}=34)$ during physiotherapy, which was significantly different from zero $(P<0.001)$, but changes during the 10-minute period which followed were $0.9 \mathrm{~mm}$. $\mathrm{Hg}$, S.D. 6.6 $\mathrm{mm}$. $\mathrm{Hg}(\mathrm{N}=14)$ when inflation pressures were increased and $-1.3 \mathrm{~mm}$. $\mathrm{Hg}$, S.D. $3.7 \mathrm{~mm}$. $\mathrm{Hg}$ $(\mathrm{N}=20)$ in the group who were left undisturbed. Neither of these is significant, indicating that the increase in gradient produced during physiotherapy was not restored by hyperinflation nor did it correct spontaneously in the first 10 minutes after physiotherapy.

Arterial carbon dioxide pressure The $\mathrm{PaCO}_{2}$ of the neonates was $28.3 \mathrm{~mm}$. $\mathrm{Hg}$, S.D. $6.9 \mathrm{~mm}$. $\mathrm{Hg}$ $(\mathrm{N}=34)$ before physiotherapy, and this dropped to $25.7 \mathrm{~mm}$. Hg, S.D. $5 \cdot 2 \mathrm{~mm}$. $\mathrm{Hg}(\mathrm{N}=34)$ after the procedure. The mean of the differences was significant $(\mathbf{P}<0.001)$.

As would be expected, hyperinflation caused a significant drop $(\mathrm{P}<0.001)$ from mean $\mathrm{PaCO}_{2}=$ 26.6, S.D. $5 \cdot 4 \mathrm{~mm}$. $\mathrm{Hg}$, to $19 \cdot 2 \mathrm{~mm}$. $\mathrm{Hg}$, S.D. $8 \cdot 3$ $\mathrm{mm}$. $\mathrm{Hg}$, but little change was found among those left undisturbed. Their $\mathrm{PaCO}_{2}$ was $25.1 \mathrm{~mm}$. $\mathrm{Hg}$, S.D. $5.0 \mathrm{~mm}$. $\mathrm{Hg}$ after physiotherapy and 24.5 $\mathrm{mm}$. $\mathrm{Hg}$, S.D. $4.8 \mathrm{~mm}$. $\mathrm{Hg}$ at the end of the 10 minutes' observation.

\section{GROUP C}

After 30 minutes of hyperinflation the mean $\mathrm{PaO}_{2}$ of the patients had increased by a mean value of $4.2 \mathrm{~mm}$. $\mathrm{Hg}$. The greatest increase was $8 \mathrm{~mm}$. $\mathrm{Hg}$ and the smallest $2 \mathrm{~mm}$. $\mathrm{Hg}$ over the period. There was no change in the $\mathrm{PaO}_{2}$ of the eight subjects followed for the natural course $\mathrm{PaO}_{2}$.

During the same time the mean $\mathrm{PaCO}_{2}$ of the patients who were hyperinflated fell by $7 \mathrm{~mm}$. $\mathrm{Hg}$. The greatest fall was $16 \mathrm{~mm}$. $\mathrm{Hg}$ and the smallest $3 \mathrm{~mm}$. Hg. Once again there was no difference in the $\mathrm{PaCO}_{2}$ of those followed for the natural course of blood gas changes.

\section{DISCUSSION}

As found in the previous study (Holloway et al

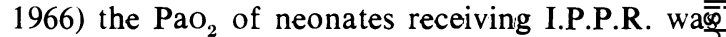
significantly below that of a comparable group of normals, thus substantiating what is now a welk known fact ; patients receiving artificial ventilation often have hypoxaemia unless oxygen enrichmen $\Phi$ of inspired air is provided (Nealon et al., 1966 $\overrightarrow{\dot{\vec{H}}}$ Gold and Helrich, 1967).

The most obvious cause of hypoxaemia, under ventilation, must be excluded before more exotifo reasons are sought. That the babies in this stud. were not being underventilated can be seen from the $\mathrm{PaCO}_{2}$ of the respirator patients which waN below normal (mean $28 \mathrm{~mm}$. Hg, S.D. $7 \mathrm{~mm}$. Hg $\mathbf{N}=34$ ), indicating that if anything they were being hyperventilated.

The effect of chest physiotherapy and hypes inflation on these oxygen levels was disappoin 5 ing. Neither physiotherapy, nor hyperinflationg nor hyperinflation plus physiotherapy restored $\mathrm{PaO}_{2}$ to normal. On the contrary, physiotherap星 produced a small but significant fall in $\mathrm{PaO}_{2}$ assos ciated with a widening of the alveolar to arteriag gradient for oxygen $\left(\mathrm{PAaO}_{2}\right)$ and we have becom? interested in what change occurred in the patient?

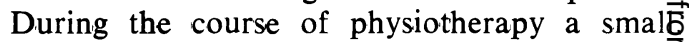
but significant $(\mathrm{P}<0.001)$, fall in mean $\mathrm{PACO}_{2}$ o $3.0 \mathrm{~mm}$. $\mathrm{Hg}$ took place. This, according to the alveolar air equation (Rahn and Fenn, 1955 would cause a comparable rise in $\mathrm{PAO}_{2}$. Th产 magnitude of this latter rise, depending on the respiratory gas exchange ratio $(\mathbf{R})$, would var from $2.5 \mathrm{~mm}$. $\mathrm{Hg}(\mathrm{R}=1.2)$ to $3.1 \mathrm{~mm}$. Ho $(\mathrm{R}=0.8)$ and, if the lung behaved as a perfect tonometer, would be transmitted to the arteria blood. As has been shown, the predicted rise did not occur; the lung did not behave as a perfect tonometer, but instead there was a significant fat in $\mathrm{PaO}_{2}$.

Not only did a fall in partial pressure occur, but this was accompanied by a fall in saturation. It is possible to compute the saturation of arteriat blood from the $\mathrm{PaCO}_{2}, p \mathrm{H}$, and base excess, an£ to show that this was significantly $(P<0.005)$ lowe after physiotherapy than before, the mean drop for the whole group being $0.5 \%$.

This change has been calculated on the assumption that all of the haemoglobin in the blood of the babies was adult. In the event of all the haem globin being foetal, a fall would also hav occurred but would probably have been \&f different magnitude. From the work of Darling Smith, Asmussen, and Cohen (1941) it is possible to estimate the change in log saturation of foeta 
haemoglobin (mean -0.032, S.D. 0.598) and to show that, since the mean $\mathrm{PaO}_{2}$ of the babies was $50.6 \mathrm{~mm} . \mathrm{Hg}$, the fall in saturation, which would have occurred had all the haemoglobin been foetal, would be about $0.75 \%$. In either event, or if the blood contained a mixture of adult and foetal haemoglobin, the effect would have been the same: a small fall in saturation.

While alveolar oxygen pressure was rising, arterial saturation was falling, and, at the same time, there was an increase in arterial $p \mathrm{H}$. This latter change exaggerated the effect of the other two, since the oxygen pressure of blood with a given saturation is lowered by increasing the $p \mathrm{H}$ (Bohr effect).

Following physiotherapy, the patients were divided into two groups. Twenty babies were followed for the natural course of blood changes during the 10-minute period following physiotherapy.

There was no significant change in blood $p \mathrm{H}$ of these babies, but mean saturation increased by $0.3 \%$, S.D. $0.28(\mathrm{P}<0.001)$ and there was a small but significant increase in mean $\mathrm{PaO}_{2}$ of $1.7 \mathrm{~mm}$. Hg, S.D. $1.22(\mathrm{P}<0.001)$.

The remainder of the babies had their inflation pressure increased by $10 \mathrm{~cm} . \mathrm{H}_{2} \mathrm{O}$, and in them the changes were greater. Saturation went up by $1 \cdot 2 \%$ and $\mathrm{PaO}_{2}$ by $6.4 \mathrm{~mm}$. $\mathrm{Hg}$. These changes were also significant. Even the mean $p H$ changes became significant, an alteration in the mean value of +0.069 occurring $(\mathrm{P}<0.001)$ as mean $\mathrm{PaCO}_{2}$ dropped by $7.35 \mathrm{~mm}$. Hg., S.D. 4.83 (P<0.001).

What actually occurred to bring about these changes in the lungs of the babies during physiotherapy and suction remains obscure. Alterations in $\mathrm{PCO}_{2}$ and $\mathrm{Po}_{2}$ influence the pulmonary vascular resistance and the distribution of gas and blood to the alveoli (Comroe, 1966; Rudolph and Yuan, 1966). Alterations in $\mathrm{PCO}_{2}$ affect cardiac output (Prys-Roberts, Kelman, Greenbaum, and Robinson, 1967 ; Tomlin, 1966). Pressure in pulmonary vessels related to those obtaining in the alveoli play a part in directing blood through the lung (West, 1967), and work in this unit indicates that lowering the $\mathrm{PaCO}_{2}$ in children with airways obstruction is often associated with a fall of oxygen pressure in their arterial blood. We consider a drop in cardiac output to be the most likely cause for the observed changes. As shown by others (Prys-Roberts et al., 1967), the cardiac output is linearly related to the $\mathrm{PaCO}_{2}$. If the cardiac output of our patients dropped while the shunt across their lungs remained the same, the admixture of the same amount of venous blood (but with a lower oxygen content) could be expected to produce the observed changes. Work along lines similar to those reported in this paper is continuing. This indicates that it is possible to reverse the direction of the oxygen changes-that is, to produce a rise after physiotherapy-by using a rebreathing technique which leaves the patient with a slightly higher $\mathrm{PaCO}_{2}$ after the procedure. We have taken this to be further evidence in favour of changes in $\mathrm{PaCO}_{2}$ being the deciding factor.

Only more work will give the final answers as to whether physiotherapy and suction produces the changes it does via one of these mechanisms or by some other such as, for example, alveolar collapse due to the suction. In the meanwhile it seems wise to regard the procedure, or perhaps the associated suction, as producing hypoxaemia.

There seems to be general agreement that it also helps to rid the patient of unwanted secretions and that in this way it prevents lung infection or is helpful in treating this condition for the same reason. Although impressions gained in the Durban respiratory unit suggest that this is true, we also have the impression that some patients succumb during vigorous and over-energetic physiotherapy, especially in the hands of inexperienced physiotherapists who may not be expert at gauging patient distress.

Our current view, based upon this study, is that physiotherapy has a side-effect in the form of hypoxaemia. We therefore feel that oxygen enrichment of inspired air should be used during physiotherapy to the chest of very ill patients. Since all the respirator patients in this study had a $\mathrm{PaO}_{2}$ below normal, we also believe, as do others (Gold and Helrich, 1967 ; Nunn, Bergman, and Coleman, 1965), that the inspired air of all respirator patients should be enriched with oxygen.

The question whether automatic sighing devices are of value must also remain undecided.

Whether intermittent large tidal volumes are a practical means of restoring arterial oxygen pressures in long-term I.P.P.R. remains to be proved. There is little room for doubt that relatively high pressures (in the order of $40 \mathrm{~cm} . \mathrm{H}_{2} \mathrm{O}$ ) can increase $\mathrm{PaO}_{2}$ in patients receiving short-term I.P.P.R. (Nunn et al., 1965 ; Bendixen et al., 1964), but we have encountered practical difficulties in applying this to babies and in particular to those on I.P.P.R. for periods of days. Although it is difficult to prove, it is our impression that, while these pressures may be safe during the first few days of I.P.P.R., their use during the days that follow is sometimes associated with pneumothorax. Presumably this is due to the development of areas of infection or some such process which weakens the 
resistance of their lungs to rupture. It was for this reason that we chose to study slightly lower pressures on recently induced hypoxia (such as that occurring during chest physiotherapy) as well as pressures in the same order of magnitude on such patients whose underlying abnormality had operated for longer.

The mean pressures to which the babies were subjected was $33 \mathrm{~cm} . \mathrm{H}_{2} \mathrm{O}$ after the increase had been brought about.

As has been shown above, this quickly restored the small decrease in arterial oxygen pressure which physiotherapy had brought about. However, it failed to return their $\mathrm{PaO}_{2}$ to normal. This seemed to indicate that, while hyperinflation may be of value in reversing recently induced hypoxia, it cannot reverse long-standing changes. This is borne out by two further pieces of evidence. There was a disappointing increase in the $\mathrm{PaO}_{2}$ of the patients in group $\mathrm{C}$ who received hyperinflation for 30 minutes. At the end of this time they were little better off than when they started. The maximum increase in $\mathrm{PaO}_{2}$ was $8 \mathrm{~mm}$. $\mathrm{Hg}$ in a baby whose $\mathrm{PaO}_{2}$ breathing air was $58 \mathrm{~mm}$. $\mathrm{Hg}$. The second piece of evidence against hyperinflation being of value in long-standing $\mathrm{V} / \mathrm{Q}$ abnormalities is the finding that it reversed hypoxia, not by restoring the ventilation perfusion point but by hyperventilation which induced a new change whose direction was opposite to that which caused the deterioration.

We should like to thank Dr. H. R. J. Wannenburg, Medical Superintendent of King Edward VIII Hospital, Dr. B. V. Shulze, head of the Department of Physical Medicine, and Professor D. Crichton, head of the Department of Gynaecology and Obstetrics, for the facilities they made available. Thanks are also due to Dr. S. Ripley and Mr. W. L. Eaton for their constructive criticism. This work was supported by grants from the Wellcome Trust and made possible by the co-operation of the Hospital Services Division of the Natal Provincial Administration.

\section{REFERENCES}

Bendixen, H. H., Bullwinkel, B., Hedley-Whyte, J., and Laver, M. (1964). Atelectasis and shunting during spontaneous_ventilatiō in anaesthetized patients. Anesthesiology, 25, 297.

- Hedley-Whyte, J., and Laver, M. B. (1963). Impaired oxygen $\overline{\mathcal{S}}$ tion in surgical patients during general anesthesia with controlle ventilation. New Engl. J. Med., 269, 991.

Brachi, M., Christopher, R., Mack, B., and Holloway, I:R. (196命 Mixing and standardizing cases for use in measuringlpulmonary function. S. Afr. med. J., 41, 1096.

Comroe, J. H. (1966). The main functions of the pulmonary circulation. Circulation, 33, 146.

Darling, R. C., Smith, C. A., Asmussen, E., and Cohen, F. M. (194 $\overrightarrow{\mathrm{Cu}}$ Some properties of human fetal and maternal blood. J. clim. Invest., 20, 739.

Desai, S. D., Holloway R., and Thambiran, A. K. (1968). Modificatio of the Laughlin waterbath for the imicro-oxygen electrod S. Afr. med.J.., 42, 454 .

- _ and Wesley, A. G. (1967). A comparison between arterial and arterialized capillary blood in infants. Ibid., 41, 17

Feychting, H., and Settergren, G. (1966). Automatic sighing-Cevice Lancet, 1, 26.

Gold, M. I., and Helrich, M. (1967). Ventilation and blocd gases anaesthetized patients. Canad. Anaesth. Soc. J., 14, 424.

Holloway, R., Desai, S. D., Kelly, S. D., Thambiran, A. K., Strydone S. E., and Adams, E. B. (1966). The effect of chest physiotherap on the arterial oxygenation of neonates during treatment tetanus by intermittent positive-pressure respiration. $S$. Afr. med $J ., 40,445$.

__ and Thambiran, A. K. (1967). A self-inflating cuffed/neona tracheostomy tube suitable for intermittent positive-pressure respiration. Lancet, $2,345$.

Korkeila, J. (1968). How to get the Engström respirator to sigh durin anesthesia. Anesthesiology, 29, 148.

Nealon, T. F., Prorok, J. J., Gosin, S., and Fraimow (1966). Impaire oxygenation with prolonged continuous ventilatory suppor Ann. Surg., 164, 558.

Nunn, J. F., Bergman, N. A., and Coleman, A. J. (1965). Facto influencing the arterial oxygen tension during anaesthesia with artificial ventilation. Brit. J. Anaesth., 37, 898.

Prys-Roberts, C., Kelman, G. R., Greenbaum, R., and Robinsol R. H. (1967). Circulatory influences of artificial ventilation during nitrous oxide anaesthesia in man. Ibid., 39, 533.

Rahn, H., and Fenn, W. O. (1955). A graphical analysis of the respired tory gas exchange. The American Physiological Society, Washings: ton, D.C.

Rosen, M., and Hillard, E. K. (1962). The effects of negative pressurg during tracheal suction. Anesth. Analg. Curr. Res., 41, 50.

Rudolph, A. M., and Yuan, S. (1966). Response of the pulmonaryु vasculature to hypoxia and $\mathrm{H}^{+}$ion concentration change J. clin. Invest., 45, 399.

Saling, E. (1964). The endoscopic technique of obtaininglfoetal bloot for microanalysis. Germ. med. Mth., 9, 449.

Siggaard Andersen, O., Engel, K., Jørgensen, K., and Astrup, P. (1960연 A micro method for determination of $\mathrm{pH}$, carbon dioxide tension, base excess and standard bicarbonate in capillary blood. Scand
clin. Lab. Invest., 12, 172 .

Tomlin, P. J. (1966). Quantitative effects of changes in arterial pH and $\mathrm{PaCO} 2$, upon cardiac output during halothane anaesthesied in dogs. J. Physiol. (Lond.), 185, 66P.

West, J. B. (1967). Pulmonary function studies with radioactive gase Ann. Rev. Med., 18. 459 